
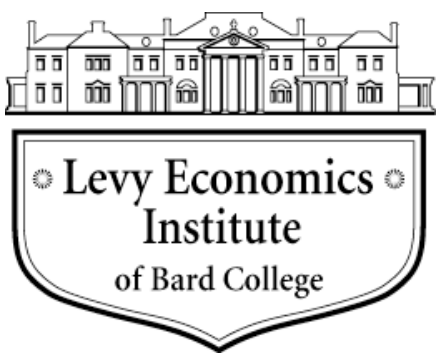

Working Paper No. 841

\title{
Marx's Theory of Money and 21st-century Macrodynamics
}

by

Tai Young-Taft*

Levy Economics Institute of Bard College

July 2015

*Contact: tyoungtaft@simons-rock.edu

The Levy Economics Institute Working Paper Collection presents research in progress by Levy Institute scholars and conference participants. The purpose of the series is to disseminate ideas to and elicit comments from academics and professionals.

Levy Economics Institute of Bard College, founded in 1986, is a nonprofit, nonpartisan, independently funded research organization devoted to public service. Through scholarship and economic research it generates viable, effective public policy responses to important economic problems that profoundly affect the quality of life in the United States and abroad.

\author{
Levy Economics Institute \\ P.O. Box 5000 \\ Annandale-on-Hudson, NY 12504-5000 \\ http://www.levyinstitute.org
}

Copyright $(C$ Levy Economics Institute 2015 All rights reserved

ISSN 1547-366X 


\begin{abstract}
Marx's theory of money is critiqued relative to the advent of fiat and electronic currencies and the development of financial markets. Specific topics of concern include (1) today's identity of the money commodity, (2) possible heterogeneity of the money commodity, (3) the categories of land and rent as they pertain to the financial economy, (4) valuation of derivative securities, and (5) strategies for modeling, predicting, and controlling production and exchange of the money commodity and their interface with the real economy.
\end{abstract}

Keywords: Macroeconomics; Marx’s Theory of Money; Monetary Theory; Transformation Problem

JEL Classifications: B51, E11, G13 


\section{INTRODUCTION}

Contemporary discussions of Marx's theory of money center on the advent of fiat currencies not backed by a gold standard (Foley 1982, 1983, 2005; Moseley 2005, 2011). However, Marx typically claimed that money was a commodity—gold in particular (Germer 2005). As gold became detached from currency traded in daily transactions it became increasingly difficult to presume gold mediated the value relationship between money and commodities. One possible reason why this lead to the profession of a monetary relationship of fiat currencies (say paper notes issued by the state or bank credit) relative to commodities was there was need to substantiate the price relationship between money as a measure of labor value and commodities as embodied labor exchanged for valuable money, which commodity money fulfilled through the labor theory of value. Without such positioning, it may be that the relationship between money and commodities becomes unviable, or the labor theory of value becomes unviable (if there is no such money form to enable social communication of exchange).

We forward two critiques of Marx and this literature which we see as underscoring difficulties in articulating non-commodity theories of money and explaining financial crises and their consistent lead (Kindleberger 1993) relative to business cycles in modern history. These critiques pertain to (1) a tendency for prices to lie within a region in some sense close to labor values $^{1}$ and (2) the failure to apply the definition of a commodity (something that is produced which is not for personal use but to be sold) to financial assets, perhaps because of (a) the social aspect of their production; (b) because there is negligible labor in a physical financial asset, whether it be a paper IOU or particular magnetism in an electronic network; and (c) the discount for future earnings is undefined.

This paper argues (1) equilibrating dynamics of prices need not go to a region close to their equality with labor values; (2) it is possible to conceive of money and other financial assets as materially produced commodities; and (3) operational allocation of capital to financial and

\footnotetext{
${ }^{1}$ By "close to" we mean specifically (1) proportional to the organic composition of capital of an industry, (2) proportional to the organic composition of capital of gold production, (3) proportional to their ratio, or (4) any other set of prices which are "conserved" in the sense of Foley $(1982,1983)$. In the case that "the value of money" is "the ratio of aggregate direct labor time to aggregate value added," Foley $(1982$, p. 41) states "the sum of the value gained and lost by all the producers in exchange will be zero;" that is, "value is created in production but conserved in exchange." He articulates this point, citing himself, in Foley (1983, p. 7): "Only with this convention for defining the value of money will we be able consistently to maintain the idea that money is a form of value; that value is conserved in exchange; and that the expenditure of labor creates value."
} 
real sectors provides a more realistic depiction both of what investors actually do and business cycle dynamics.

\section{EQUILIBRATING DYNAMICS OF PRICES NEED NOT GO TO A REGION CLOSE TO LABOR VALUES}

One of the great features of Marx and other classical political economists is that dynamics need not equilibrate in any meaningful sense, and may follow systematically divergent dynamics relative to their attractive centers which allow for, in the case of Marx, greater centralization of capital, scope of exploitation, and social reproduction. For example, if we consider innovations in some set of sectors and labor and investment to follow the path of cost minimization toward an equilibrium of price and labor value, there may be structural reasons that certain sectors may have prices far away from their labor values. This may be due to obvious pressures, such as state protection, or due to dynamics that cyclically pass on revenue in the form of inflated prices between sectors.

In order for the labor theory of value to hold, value must be conserved in exchange (Foley 1982, p. 41; Foley 1983, p. 7). However, price need not be; the laws of motion of the system are not negated by such dynamics. Hyperinflations are an example of where price may be said to explode, which is not conservation.

Indeed, many of the most salient features about the modern economy may be explained by systematically deviating prices relative to such centers and these prices may be among those that most contribute to the social division of labor. The theory of monopoly power as an event within complex laws of motion, though it perhaps has yet to be fully theorized, may in part be seen as systematic deviations of prices from labor values, and there may be theoretical reasons for this. Mandel, for example, regarding Marx's discussion of land pricing as capitalization of future rent, claims, "We are justified in saying that what Part Six of Volume 3 is really about is the more general problem of monopoly giving rise to surplus profit" (Mandel 1991, pp. 12-13). Likewise, the state could be seen in part as a conduit for such pricing flows, concomitant with the violence and primitive accumulation it implies. Exchange rates in low-price-value-added (equivalent labor time value added) countries relative to high-price-value-added countries may feed back disequilibrium prices into the system to facilitate greater international aggregate exploitation (a process itself clearly facilitated by regulating immigration on behalf of the state). Lastly, inflation may also be considered relative to divergent price dynamics and the extension 
of the division of labor and concentration of capital, in a move away from wage-led inflation dynamics.

\section{MARX'S THEORY OF MONEY AND ITS RELATION TO FINANCE}

Since the inception of large-scale modern finance with bills of exchange associated with trade fairs, finance has been a particularly lucrative, voluminously traded, valuable, and crisis-prone enterprise (Kindleberger 1993). In this regard, it may be desirable to consider financial claims relative to enterprises' revenue-generating streams as a concrete object of economic analysis, for example rather than prescribing psychological features to financial participants and their collective activity, or describing them as "fictitious" (Marx 1991). Finance may be regarded as a component part of economic activity that serves as alternative ground for capital investment. This claim relative to money has been made by Marx, insofar as he claims money is a commodity and subject to the labor theory of value.

Marx's substantive contribution to the classification of money begins with the idea that money is a commodity and commodity economies follow the labor theory of value; that is, that a particular commodity form comes to be the medium of intermediation of commodity exchange, and - in some substantive sense - the labor value of the money commodity relative to another commodity constitutes the price of that commodity. This brings great concretism to the analysis of money and its valuation relative to the real economy. It also points the way to dynamics relative to the valuation of social processes that change society's technology, in particular, changing socially necessary labor time relative to a set of interdependent industries, which then have to dynamically reorient themselves toward new pricing forces. This is due to the fact that the value of money is fixed and acts as the unit of account for competing capitals by which to measure cost-reduction efforts.

However, the body of Marx's discussion of credit, financial speculation, stock valuation, and other financial asset dynamics relies on the concretism of the money commodity and a relatively unimodal conception of socially necessary labor time vis-à-vis industrial sectors pertinent to the economy at hand. In particular, dynamics are generally said to move in the direction of their gravitational centers, rather than following orbits or other paths that do not correspond to a region close to the point where prices are equal to socially necessary labor 
times. This may inhibit a free-form analysis of financial asset price dynamics as competitive and instrumental relative to the real economy.

\section{FINANCIAL ASSETS AS COMMODITIES}

Our general claim is that in order to bring concretism to the analysis of financial assets, we can identify them as produced inputs into productive processes - that is as commodities, and the definition of the money commodity lends itself to its identification with a set of financial assets which trade for other commodities (notably, other financial assets); we hope to claim (1) financial assets can be considered to be commodities and (2) a set of financial assets that fulfill the definition of money together constitute the money commodity.

To consider the claim that financial assets can be considered to be commodities, note that any financial asset is a material, produced commodity. Consider the examples of a paper bank note and an electronic asset in this regard. Clearly, the labor expended in the production of the note is less than the potentially substantial exchange value it has. Nonetheless, it is a materially produced use value, not intended for use of the one producing it, but for exchange, making it a commodity, albeit a commodity whose price is much different than its labor value in the standard circumstance.

Now take the electronic financial asset. Here, the social character of production is more relevant, because the financial asset exists as a certain magnetism (set of magnetisms) relative to the hard drives of the quorum of networked computers that constitute a financial database. The production of such an asset, say an issuance of stock for a firm, happens relative to the relevant servers, which is then utilized in the network. Again, here the labor is even less significant than the case of a paper note, which at least has some (albeit still negligible) labor value. However, it is clearly a produced commodity, produced with material inputs (electrons and computational execution apparatus), which can be fed back into the system to produce another such asset. As such, it is possible to extend the definition of money as the commodity exchanged for other commodities to a set of financial assets that fulfill the function. 


\section{HETEROGENEITY OF THE MONEY COMMODITY}

The money commodity is the commodity that is traded or exchanged for other commodities. One issue with this definition, however-or more specifically, the de facto identification of the money commodity with gold - is that it obviates the possibility of one or more money commodities, or more appropriately, it negates the possibility of heterogeneity within the money commodity. Much of Marx's substantive contributions rely on modern mathematical language that prescribes variables, their averages and aggregates, to functions that map them into correspondent spaces. This does not negate his historical materialism to the extent that these functional specifications are themselves part of history, and fulfill particular human ends. In any case, throughout modernity, a variety of material objects have filled the technical capacity of money, such as bills of exchange, silver, gold, and copper. Silver and gold, for instance, had dynamic and interesting roles relative to mercantilism (Kindleberger 1993). These commodities collectively at any point in time might be considered to be the money commodity, the set which exchanges other commodities for itself. This functional description is in line with Marx's broader scientific orientation.

If we turn our attention to the contemporary money commodity, it may be claimed that its primary constituent is bank credit, as mediated by state credit. However, other financial assets likewise are traded for each other, and so they too may be considered part of the money commodity.

Consider the examples of collateral and options. Collateral is a state-contingent claim relative to repayment of an IOU. Given the event of failure to repay, the borrower effectively trades the collateral for the owed asset. Though this only happens some share of the time to a certain degree, functional abstraction is still operational on both the particular and aggregate levels; that is, aggregation as an analytic devise is not a problem. Options are also statecontingent claims relative to price differentials of contract and market. If the "underlying"- the asset a derivative is defined on (e.g., an option to buy a stock) - is priced pretty, the option holder may trade the option for the claim (or negative claim) and clear at market price (or retain cash if they sell the underlying).

The same argument can be applied to bank credit itself. The issuer can be said to be trading a state-contingent IOU for credit. IOUs are defined conditionally on the ability to pay and are produced material commodities. 
State-contingent claims that can affect exchange of financial assets more generally may be thought of as elements of the money commodity. Contingent claims can be said to be traded for other commodities to the extent that there exists a positive probability that they will change hands given the advent of an event. This is not merely a turn of phrase. The state contingent aspect of financial transactions significantly increases liquidity in financial markets. ${ }^{2}$

\section{PRODUCTION OF THE MONEY COMMODITY}

The question of the production of the money commodity in this context pertains to the question of production and exchange in Marx. ${ }^{3}$ In this context, we stress the social aspect of production relative to credit in Marx's exposition (Marx 1991). We say that bank money and financial assets are capitalized in the same sense that land is, that is, relative to all future rents. However, when neoclassical theorists solve for this they generally assume perfect competition, and so the discount rate is set so that the cost of finance is equal to its capitalized return (Ross et al. 2012). This obviates future joint effects of inputs and products relative to pricing and production.

For example, if you put up an underlying as a margin requirement to take a position in derivatives defined on that underlying, both collateral and investment provide information about each other, and can have mutually reinforcing dynamics (possibly in opposite directions). Not accounting for this in a discounting of future revenue misses much of the relevant dynamic content of the system.

Similar critiques can be made of categories pertaining to such capitalization in Marx. For example, if you set the discount using the average or target ${ }^{4}$ profit rate, you also lose relevance of possible joint dynamics and path dependence of a complex system. Also, if prices do not go to a region close to their labor values, profit rates may also not go to a region close to equalization across sectors. Though this is unlikely to spell disaster in the individual case, this is unlikely to spell disaster, but in the aggregate, effects can be pronounced.

Such discounting tends to negate the socially productive aspect of credit economies Marx appropriately emphasizes - while in the individual case, dynamics relative to pricing may

\footnotetext{
${ }^{2}$ To be clear, we do not mean that liquidity as such is a monetary function; the point of Marx's theory of money is that a commodity comes to take on the equivalency of the labor value of the commodities it is traded for in a capitalist system.

${ }^{3}$ See for example Foley (1982, p. 46).

${ }^{4}$ That is, the profit rate to which profit rates converge.
} 
be functional relative to a given (if arbitrary) discount relative to projected capitalized earnings; in fact credit economies are determined in aggregate, relative to financial and real markets, and feed back into them in economically meaningful ways.

Given this, an appropriate conceptualization may be aggregate pricing of financial asset classes, which can be functionally specified in ways that articulate accounting identities and state contingency relative to other assets.

\section{MODELING MONEY, FINANCE, AND REAL CAPITAL STOCKS: LOOKING TOWARD ESTIMATION, PREDICTION, AND CONTROL}

If we then consider real financial flows, we can undertake input-output analysis of tractable partitions of such a capital space, whereby tractable partition we mean aggregate classes of capital at the national level relative to concerns of (1) data availability, (2) signal, and (3) analytic tractability. Here, cost-minimizing competition may relate to optimization, for example, in information theoretic terms.

We could use the language of stochastic birth-death processes to do this. Here, assets' stock values are measured as probability distributions relative, for example, to the next period. The means of such a distribution would indicate the probabilistic expectation of that variable in the next period, and the system would be a set of such mean flows. Stock values grow-are produced - according to an appreciation (capital gains) or new issuance of a promise to pay at a market price which does not lower the price of the aggregate class such that its aggregate value is less than or equal to its aggregate value prior to the issuance. As such, assets belonging to the set of commodities in the money commodity set can be traded for assets identified as the commodities they can be traded for, but exchange as such — structurally and on average - does not count as an increase or decrease in the stock of the assets themselves. If they do increase, this counts either as a positive price movement - away from the (negligible) price where they would meet their labor values-leading to an appreciation (greater than any death of the value of the capital asset) or an issuance at a price such that aggregate value increases. This movement constitutes a productive process both in the sense of producing a material commodity and relative to the social valuation process that allocates prices and induces division of labor. If the aggregate value of the asset class declines, this may be seen as a manifestation of the falling rate of profit relative to an asset class. Cyclical dynamics within and between the financial and real asset classes constitute the business cycle. 
In this context, one could consider turbulent dynamical closures for money-capital aggregate identities in national accounting strategies, as well as over the counter and via statecontingent contracts, such as margins, collateral, and relative to maturity structure, to define the processes.

This turbulent strategy contrasts markedly with activities at the Fed and ECB relying on stochastic dynamic general equilibrium (SDGE) models (all with rather poor prediction to date [Alessi et al. 2014]) and follows weather and climate science which has met with substantive novel success in certain hard and complex problems (Majda and Harlim 2012).

In this context, one could use the Bayesian updating interpretation of relative entropy to optimize over input coefficients by minimizing relative entropy of a computed prior density relative to an updated posterior and test for prediction and control of some set of real/simulated data. Using this optimization criterion one can select an optimal policy vector, composed of, for example, a monetary flow, a fiscal flow, and a set of regulatory dams, that minimizes the same as a strategy of real-time stochastic control. This could apply not just to monetary policy in the sense of interest-rate targeting and fiscal policy as traditionally understood, but include interventions and transaction control in core financial markets.

We lastly orient the reader to which asset classes one may consider and how one might consider their interaction. Three points of attention are (1) the constitution of major asset classes, (2) availability of data for major asset classes, and (3) computational feasibility of the size of our system.

With regards to (1), one might consider capital stock, money (M1), private credit in terms of bank loans and corporate bonds, market valuation of equities, and value (price) of outstanding derivatives contracts.

In this framework, M1 is considered a produced, traded, and productive aspect of the economy. All such commodity classes as enumerated above are traded for money, for example, if one wants to buy an element of another class or another element within a class. Likewise, bank loans and other bank finance activities are due to and dynamically feed back into money production and valuation. Currency crises, for example, are points when such dynamic interface comes to the fore. M1 additionally may relate to currency and interest rate derivatives.

With regards to private credit, it would be useful to come up with a maturity distribution, though the utility of this should be traded off relative to (3), and possibly (2). Maturity- 
productivity dynamics may be seen as the central problem of the economic system. It may be useful to disaggregate or distinguish between bank credit and bond valuation.

With regards to derivatives, it would likewise be interesting to disaggregate across instrument class (both across contract - option, forward, future, swap - and underlying - credit, interest rate, currency, etc.), though again consideration must be paid to (3) and (2). Likewise, it is by no means agreed that the market price of the contract represents the "value" of the contract; should we consider the value of the underlying, the value-at-risk? The axiom of the program posits a system of valuation relative to this problem and can be assessed by the program metrics.

Additionally, in considering modeling the processes, one can consider margin actions or more generally collateral requirements as state contingent claims that communicate across asset classes. We remind the reader, for example, of the importance of credit-backed securities in the recent financial crises in the context of margin calls and the glut of treasury bills in the late 1990s that increased complexity across asset classes.

Finally, the role of the state should be explicitly considered relative to public debt and its relationship to bank credit, as well as the state's role in contributing to capital stock.

Models can then be compared relative to behavioral class and fit and predictive metrics. ${ }^{5}$

\section{CONCLUSION}

Today, as in much of modern history, it is apparent that real- and financial-money classes do not serve alternative economic functions primarily over the course of economic development, but rather constitute alternative and competing outlets for profit-seeking differentials of broad-based capital. It is, however, radically more apparent and emphatic now that we have 24-hour-a-day, 7-day-a-week international electronic markets, hosting a royal menagerie of jointly referenced and composite instruments. This is brought into stark relief accounting for contemporary financial crises around the world.

We agree that (1) the actual labor invested in the physical object that is a financial asset - whether it be a piece of paper or a particular magnetism on an electronic network —is

\footnotetext{
${ }^{5}$ Lastly, as an aside, we might relate this to the neoclassical program by formally characterizing time paths of functions mapping observed/predicted trajectories to Pareto equilibria with an eye to understand systematic functional externalities over time and how this may relate to optimization (and concomitantly prediction and control).
} 
negligible and (2) that financial asset prices are therefore "fictitious" to the extent that they do not represent labor value. However, the point is that commodities, where Marx begins his analysis, are inputs into productive processes which produce other commodities, and as long as we're willing to give up the ghost of price — which is in fact only instrumental relative to the division of labor - we should be able to conjoin the analysis of money, finance, and the real economy in ways that respect their codependence. 


\section{References}

Alessi, L., Ghysels, E., Onorante, L., Peach, R., and Potter, S. 2014. Central Bank Macroeconomic Forecasting during the Global Financial Crisis: The European Central Bank and Federal Reserve Bank of New York Experiences. Federal Reserve Bank of New York Staff Reports No. 680.

Foley, D. 1982. "The Value of Money, the Value of Labor Power, and the Marxian Transformation Problem.” Review of Radical Political Economics 14: 37-47. 1983. “On Marx’s Theory of Money.” Social Concept 1(1): 5-19. 2005. "Marx's Theory of Money in Historical Perspective.” In F. Moseley, ed. Marx's Theory of Money. Basingstoke and New York: Palgrave Macmillan.

Germer, C. 2005. "The Commodity Nature of Money." In F. Moseley, ed. Marx's Theory of Money. Basingstoke and New York: Palgrave Macmillan.

Kindleberger, C. P. 1993. A Financial History of Western Europe. New York and Oxford: Oxford University Press.

Majda, A. J., and Harlim, J. 2012. Filtering Complex Turbulent Systems. Cambridge: Cambridge University Press.

Mandel, E. 1991. “Introduction.” In Marx, K., ed. Capital: Volume III. London: Penguin Classics.

Marx, K. 1991. Capital: Volume III. London: Penguin Classics.

Moseley, F. 2005. Marx's Theory of Money: Modern Appraisals. Basingstoke and New York: Palgrave Macmillan.

2011. 'The Determination of the 'Monetary Expression of Labor Time' ('MELT') in the Case of Non-commodity Money." Review of Radical Political Economics 43(1): 95105.

Ross, S., Westerfield, R. W., and Jaffe, J. 2012. Corporate Finance, $10^{\text {th }}$ Edition. New York: McGraw-Hill. 